\title{
¿SE PUEDE HABLAR DE UN ENTRAMADO POLÍTICO RELIGIOSO EN EL PROCESO DE INDEPENDENCIA DE PORTUGAL?
}

\author{
José Ma SOTO RÁBANOS \\ Instituto de Historia CCHS (CSIC)
}

RESUMEN: En este trabajo reflexiono sobre la contribución de los poderes civiles y eclesiásticos locales al proceso de independencia de Portugal. Tomo como límite «a quo» el gobierno de Enrique y Teresa (ca. 1095) y como límite «ad quem» la emisión de la bula "Manifestis probatum» por el papa Alejandro III (23 de mayo de 1179). Recorro los acontecimientos que entiendo afectan más directamente al tema, basándome en las fuentes ya conocidas y en el análisis de la abundante bibliografía sobre el tema. A través del análisis de los datos y de mi interpretación de los mismos, llego a la conclusión de que el poder civil, con Alfonso Enríquez a la cabeza, fue el elemento axial del proceso de independencia de Portugal, proceso al que la iglesia local no apoyó institucionalmente, sino a niveles casi particulares, básicamente a través de Juan Peculiar y su entorno. El papado, reacio en principio, accedió después de treinta y seis años de trabajo diplomático, una vez que fue consciente de la viabilidad de Portugal como reino independiente bajo su protección en una Hispania plurimonárquica.

Palabras clave: Portugal. Condado. Reino. Frontera. Iglesia local. Papado.

ABSTRACT: In this article I consider the contribution of the civil and ecclesiastical local powers to the process of independence of Portugal. I choose as chronological point of departure the period of government of Henry and Theresia (ca. 1095), and as final date the issue of the $\mathrm{Pa}$ pal bull of Alexander III «Manifestis probatum» (23rd. of May 1179). I pay attention to the events that I consider that are directly related to this problem, taking into account the already known sources and the abundant bibliography about this question. Through the annalysis of the facts and my own interpretation of them, I arrive to the conclusion that the civil power, with Alfonso Enriquez at the front, was the central element in the process of independence of Portugal, that was not supported by the local Church as an institution, but only by some of its members, mainly by Juan Peculiar and its circle. The Papacy, reluctant at first, approved the independence after thirty-six 
years of diplomatic efforts, when it realised that Portugal was viable as an independent kingdom under its protection in an Hispania divided in several kingdoms.

KEY WORDS: Portugal. County. Kingdom. Frontier. Local Church. Papacy.

\section{PRELIMINARES}

Como nasceu Portugal. Así titulaba Damião Peres su breve estudio sobre la concepción y el nacimiento de Portugal como reino independiente, estudio que vería numerosas ediciones desde la primera de Porto en $1938^{1}$. Antes y después de él los estudiosos que se ocupan de la historia portuguesa se han hecho esa misma pregunta, con respuestas no del todo uniformes. Esta falta de uniformidad no se debe a los datos y hechos básicos que se tienen en cuenta y se consideran por todos como ciertos, sino a la falta de seguridad respecto de algunos otros hechos para los cuales la documentación no parece suficientemente firme; y se debe, sobre todo, a las interpretaciones diversas que unos y otros autores dan a los datos sobre los que trabajan.

El tema es amplio y está tratado repetidamente por los historiadores, muy en particular, como es lógico, por los historiadores portugueses. Como señala José Mattoso, esta cuestión «tem feito correr muita tinta» ${ }^{2}$. Fuera de las páginas que dedican al tema las Historias de Portugal de carácter general, como las de Alexandre Herculano, Pinheiro Chagas, Oliveira Martins, Fortunato de Almeida, A.H. de Oliveira Marques, J. Veríssimo Serrão, la História de «Barcelos» bajo la dirección de Damião Peres, el Diccionario de História de Portugal bajo la dirección de Joel Serrão, la Historia de Portugal bajo la dirección de José Mattoso, la Historia Religiosa de Portugal bajo la dirección de Carlos Moreira Azevedo, la História Eclesiástica de Portugal de Miguel de Oliveira, etc., son muchos y variados los estudios que tratan más o menos directamente sobre el origen, la formación y la consolidación de Portugal desde perspectivas diversas: política, economía, sociedad, derecho, religiosidad, literatura, mentalidad. Trabajos de los autores mencionados y de otros bien conocidos como: Enrique da Gama Barros, José Leite de Vasconcelos, João Lúcio de Azevedo, Carl Erdmann, Marcelo Caetano, António José Saraiva, Torcuato de Sousa Soares, Paulo Merêa, Pierre David, Mário Martins, Francisco da Gama Caeiro, Isaías da Rosa Pereira, António Cruz, Humberto Baquero Moreno, José Marques, Manuel A. Rodrigues, Aires A. Nascimento, Adão Fonseca, Helena Cruz Coelho, Maria Teresa Nobre Veloso, etc.; a los que cabría añadir todavía otros muchos estudiosos que han investigado y publicado, y lo siguen haciendo, en torno al tema ${ }^{3}$.

1 He tenido a mano la $8^{a}$ edición, Porto, Vertente, sin fecha.

2 MatToso, José: Portugal Medieval. Novas interpretaçoes, Lisboa, Imprensa Nacional, 1985, p. 87.

3 Me parecen de gran utilidad las aportaciones de ViOlante BranCO, Maria João, pues además de recoger gran parte de las contribuciones realizadas en relación con el tema, las somete a 
Por mi parte, no dispongo de documentación nueva que incorporar a este trabajo. Mi objetivo, por lo demás, no es entrar directamente en el problema del origen y la formación de la sociedad portuguesa hasta convertirse en reinonación ${ }^{4}$, aunque no sea posible dejarlo al margen totalmente, sino detenerme en el análisis de un aspecto del tema sobre el que, a mi entender, cabe profundizar, sea porque hay factores que no han sido tenidos suficientemente en cuenta, sea porque no han sido interpretados en su justo contexto, tanto por lo que se refiere a la actuación uniforme y constante de algunos poderes fácticos portugueses ante el papado, como por lo que respecta a la posición misma de la Santa Sede, que, como es sabido, pasa del silencio primero a la atención posterior y al acuerdo. En efecto, sólo al cabo de muchos años de presiones diplomáticas, el papado decidió acceder a la solicitud del hasta entonces considerado simplemente como dux del territorio portugués, aceptándole, por fin, como rex a todos los efectos y con todas las consecuencias, y prometiéndole su protección, personal para el rey y sus herederos, y comunal para el reino, a perpetuidad.

Más en concreto, mi propósito es hacer ver hasta qué punto cabe hablar de un entramado político religioso en el proceso de la independencia portuguesa, es decir, en el paso del territorio portugués de condado a reino, exponer mi opinión sobre el momento en el que se hace realidad la contribución del factor religioso al proceso independentista y poner de manifiesto las características generales que acompañan a las actuaciones de la iglesia local y a la actitud del papado. Al menos, globalmente.

un fino análisis, a través del cual expone su opinión propia, coincidente a las veces con uno u otro autor. Véanse en concreto: «Portugal no reino de León. Etapas de uma relação (866-1179)», en Fernández Catón, José María: El reino de León en la Alta Edad Media, IV: La Monarquía (11091230), León, Centro de Estudios e Investigación «San Isidoro», 1993, pp. 533-623; y Poder Real e Eclesiásticos: a evolução do conceito de soberania régia e a sua relação com a praxis política de Sancho I e Alfonso II [tese de doutoramento policopiada], Lisboa, Universidade Aberta, 1999.

4 Quizás sea excesivo hablar de reino-nación, sobre todo `por lo que se refiere al segundo término, nación, dado que en ese tiempo no se habían formado todavía las nacionalidades en el sentido político que alcanzarán más tarde, en la edad moderna. No obstante, sí se habla de nacionalidades aplicadas a personas por razón de su origen geográfico. Así, se dice, por ejemplo, Petrus, natione hispanus; o simplemente, Petrus hispanus o Petrus hispanus portugalensis. Al emplear aquí el término quiero significar, además, la cohesión interna que estimo se da en la sociedad portuguesa desde el momento en el que lucha por la independencia, la consigue y se consolida en ella. Sobre el concepto de reino aplicado a España remito a los estudios de MARAVALl, José Antonio: «El concepto de reino y 'los Reinos de España' en la Edad Media», en Revista de Estudios Políticos, 73/1 (1954), pp. 81-144; El concepto de España en la Edad Media, Madrid, Instituto de Estudios Políticos, 1954, obra en la que recoge el artículo anterior bajo el título: «El concepto de reino y la pluralidad de reinos peninsulares», como capítulo VII, pp. 359-423; Estudios de historia del pensamiento español, Madrid, Cultura Hispánica, 1967, donde recoge once estudios y seis notas sobre aspectos del pensamiento español en el medievo publicados en diversas revistas; en varios de ellos reflexiona sobre el mismo tema. Del conjunto de sus reflexiones deducimos como conclusión final la relatividad del término reino y la pluralidad de significados y de aplicaciones que admite en la España medieval. 
El tema de las relaciones del papado con Portugal durante el proceso ha sido objeto de varios y buenos estudios, destacando el de Carl Erdmann, que sigue siendo un modelo a seguir, a pesar de los años y de la afectividad bracarense, que es como decir portugalense, que se advierte en su interpretación de los hechos y en la forma de utilizar y valorar los datoss. Y es cierto que ningún estudioso ha puesto en duda el interés y la importancia del apoyo del clero portugués en el proceso independentista, siendo varios los que se ocupan directamente del tema. Avelino de Jesús da Costa, en su estudio sobre el obispo Pedro y la organización de la diócesis de Braga, se proyecta ya como precursor de los historiadores que quieren hacer caminar de la mano a ambos poderes, el político y el eclesiástico, al afirmar que:

Embora seja prematuro atribuir aspirações de autonomia política a esta luta travada por D. Pedro [se refiere a la lucha por obtener la dignidad de metropolitana para la sede de Braga\}, não há dúvida de que ela nos obriga a antecipar para o séc.XI o duelo religioso Braga-Compostela e Braga-Toledo, que, no século seguinte, acompanhou a par e passo o duelo político Portugal-Castela. É naquela luta que vão lançar raízes alguns dos principais factores religiosos que contribuiram para a formação e independência de Portugal ${ }^{6}$.

Evidentemente, el admirado y recordado profesor Avelino, aunque quiere ser prudente, se excede en estas conclusiones. Por mi parte, no pongo en duda

5 ERdmann, Carl: O papado e Portugal no primeiro século da História Portuguesa, Coimbra, Separata del Boletim do Instituto Alemão, 1935. Traducción portuguesa por J. da Providência Costa. El original alemán se había publicado en 1928. Queda complementada esta obra con una publicación anterior de documentación papal relativa a Portugal: Papsturkunden in Portugal, Berlin, Vandenhoeck \& Ruprecht, 1927. Me parece también muy interesante, aunque se refiere a un tiempo ligeramente posterior al que aquí nos ocupa, el trabajo doctoral de Nobre Veloso, Maria Teresa, que vio la luz de la imprenta hace sólo unos años con el título: D. Afonso II: Relações de Portugal com a Santa Sé durante o seu reinado, Coimbra, Arquivo da Universidade de Coimbra, 2000. Esta autora pone el acento en la teocracia papal del momento. Por su parte, en un breve estudio, SUÁREZ FERNÁNDEZ, Luis: «Factores religiosos en las relaciones entre León y Portugal (1185-1230)», en Fraternidade e Abnegação, vol. II, Lisboa, Academia Portuguesa da História, 1999, pp. 949-961, destaca, entre las ideas dominantes que rigen las relaciones entre León y Portugal, las que se refieren al fenómeno religioso. Véanse también VASCONCELOS VILAR, Herminia: «Monarquia e Igreja: convergências e oposições. De Afonso Henriques a Sancho II: Uma difícil delimitação de poderes (1128-1245)», en MOREIRA AZEVEDO, Carlos (Dir.): História Religiosa de Portugal, vol I, Lisboa, Temas e Debates, 2004, pp. 305-318.

6 Costa, Avelino de Jesus da: O bispo D. Pedro e a organizaão da diocese de Braga, Coimbra, Imprensa de Coimbra, 1959, vol. I, pp. 252-253. Se publica como Separata de la revista Biblos, XXXIII, (Coimbra 1957), pp.135-672; y XXXIV (Coimbra, 1958), pp. 1-659. Incluye un cuadernillo, fechado en Coimbra el 30 de noviembre de 1960, de «addenda et corrigenda» El autor presentó una revisión de este trabajo bajo el mismo título en el IX Centenário da Dedicaşão da Sé de Braga. Congresso Internacional. Actas, vol. I, Braga, Universidade Católica Portuguesa, 1990, pp. 379434. Themudo Barata, Manuel F.: "A Sé de Braga na formação e consolidação de Portugal», Ibid., vol. II/1, p. 12, afirma que entre los pasos de autonomía más decisivos «se encontrava a dinámica religiosa da Sé de Braga ». 
que la iglesia local, y muy en especial la iglesia bracarense, por su significado, llegara a desempeñar de algún modo un papel importante en el proceso independentista. Vistos los hechos, es justamente la convicción de que participó en el proceso la que me induce a preguntarme por un posible entramado político religioso.

No me voy a detener en examinar el periodo en que Portugal es un territorio, una región bajo el mando de determinadas familias de nobles en representación del rey de León y de Castilla, en el «viejo condado de Portugal» ${ }^{\text {, ni en }}$ el corto periodo en que aparece, a una con Galicia, bajo el gobierno del conde Raimundo de Borgoña. Entiendo, con Joaquim Veríssimo Serrão y otros ${ }^{8}$, que es a partir de la entrega del territorio a título hereditario por Alfonso VI a su hija Teresa, que casa con Enrique de Borgoña, al cual se designa gobernador del territorio, cuando se puede hablar realmente de un condado portugalense, dando al término condado un valor superior al de simple tierra, región o lugar, si bien soy consciente de que la terminología usada entonces es muy varia y poco técnica, y de que ya antes de Teresa y Enrique hay nobles que llevan título de condes en el territorio portugués.

Sobre los motivos de la creación de un nuevo condado con la desmembración de tierras de Portugal y de Coimbra del condado de Galicia, y de su encomienda a Enrique, la hipótesis más aceptada, y a mi parecer también la más aceptable, es que la decisión de Alfonso VI obedeció sólo a razones de carácter político y militar, además de familiar, del momento; político/familiar por la parte que toca a su hija Teresa, y político/militar, e igualmente familiar, por lo que respecta a Enrique, su yerno, cuyas dotes guerreras le eran bien conocidas. Se ofrecen otras hipótesis, más sibilinas y menos fundadas, como la que propone Reilly, según el cual el rey Alfonso VI quiso provocar desavenencias entre sus yernos, y primos entre si, Raimundo y Enrique, temiendo un pacto sucesorio entre ellos, cuya fecha sitúa entre diciembre de 1094 y julio de1095, en mera lógica a su tesis, pero sin que ofrezca un fundamento sólido; simplemente, le parece que a finales de 1094 se daban ya las condiciones suficientes para el pacto en cuestión`. Ch. J. Bishko sitúa el pacto diez años después, entre finales de 1104 y el verano de 1105 , lo que resulta más creíble ${ }^{10}$.

7 Según expresión de ReILly, Bernard F.: El reino de León y Castilla bajo el Rey Alfonso VI (1065-1109). Trad. Por Gaspar Otálora Otálora, Toledo, Instituto Provincial de Investigaciones y Estudios toledanos, 1989, p. 37, en referencia al norte de Portugal. La revuelta de nobles portugueses contra el rey García de Galicia es una cuestión interna y no veo fundamento para considerarla como un movimiento precursor de la independencia.

8 Veríssimo Serrão, Joaquim: História de Portugal, I: Estado, Pátria e Nação (1080-1415), Lisboa $^{3}$, Verbo, 1979, p. 76. Para Carl ERdmann, O papado..., p. 14, en la entrega de Portugal a Enrique está «a origem do condado portucalense que só agora entra na históia como um estado próprio».

9 ReILLY, Bernard F.: El reino de León..., p. 276.

10 Bishro, Charles J.: Spanish and Portuguese Monastic History, 600-1300, IX: Count Henrique of Portugal, Cluny, and the antecedents of the Pacto Sucessório, London, Variorum Reprints, 1984, pp. 155190A. El volumen no tiene paginación propia; se mantiene la paginación de la revista u obra 
De otra parte, se debe admitir, y los análisis de investigadores reconocidos lo han puesto de manifiesto, que los habitantes del territorio portugués desde tiempo atrás habían venido forjando sus propias estructuras sociales, sus características territoriales. Pero nada nos permite ir más allá, de principio. Paulo Merêa no se sustrae a la tentación, en la que caen no pocos de los historiadores portugueses, de ir un poco más allá, al poner el acento en todos los hechos que durante ese tiempo pudieran interpretarse de alguna manera como señal indiciaria, aun mínima, de la voluntad de la nobleza y del pueblo de alcanzar la independencia ${ }^{11}$. Por ejemplo cuando, apoyándose en la tesis de Jacques Flach sobre los grandes linajes como creadores de nacionalidades regionales ${ }^{12}$, afirma:

É mesmo legítimo preguntar se êstes factos (de finales del s. X hasta Fernando Magno) não ajudarão a compreender a génese, necessàriamente misteriosa, da nacionalidade portuguesa. Se, como ensina J. Flach, são as grandes linhagens as principais criadoras de nacionalidades regionais, a permanência da terra portugalense sob a regência duma dinastia de caudilhos, grandes proprietários da região e com interêsses a ela íntimamente vinculados, não podia deixar de concorrer em larga escala para a plasmação dum «povo portugalense ${ }^{13}$.

La forja de estructuras sociales propias es resultado natural de toda convivencia sujeta a circunstancias comunes, y de por si no tiene por qué concluir precisamente en una separación drástica, de vida y de gobierno, respecto de una comunidad vecina. A mi modo de ver, Portugal no disponía todavía de suficientes formas propias de vida y de cultura como para dotarse de un carácter más allá de pre-nacional A vista de hoy, sin embargo, puede no parecer ilegítimo que se aprecien estos hechos convivenciales como un primer paso hacia la independencia de Portugal, aunque puestos en aquel tiempo no podríamos predecirlo.

Por todo lo dicho, y porque me llevaría fuera del propósito central de este trabajo, no he estimado oportuno detenerme en la situación anterior al conde

colectiva en que se publicaron los diversos estudios, que enriquece con una nota adicional. Los estudios primero y último, no publicados anteriormente, llevan numeración independiente. El trabajo aquí citado se publicó en Revista Portuguesa de História, 13 (1971), pp. 155-188. Las páginas 189 A - 190A corresponden a la nota adicional.

11 Mattoso, José: Portugal Medieval..., p. 87, en respuesta a un estudio de António José Saraiva, hace una observación similar: «Os historiadores portugueses têm uma tendência irresistível para se fixarem em certos momentos «altos» do passado nacional».

12 Flach, Jacques: Les origines de l'ancienne France, $X^{e}$ et XI siècles. III : La renaissance de 'État. La royauté et le Principat, Paris, Ancienne Maison L. Larose et Forcel, 1904, p. 127-142. Sospecho que Merêa se refiere al análisis de Flach sobre los grupos básicos (étnico, familiar, señorial y religioso), sobre cuyo eje gira la territorialidad en expansión o en repliegue.

13 MerêA, Paulo: De «Portucale» (civitas) ao Portugal de D. Henrique, Porto, Portucalense Editora, 1944, pp. 22-23. En este opúsculo traza la trayectoria de la tierra portugalense entre la «civitas» y el «condado». 
Enrique. Remito a los estudios realizados sobre la ocupación del espacio en la España medieval con sus connotaciones de afirmación territorial y de coherencia interna, y de brotes de rebeldía con intentos de desvinculación del poder originario ${ }^{14}$.

\section{ENRIQUE DE BORGOÑA Y TERESA}

Revisemos brevemente la actuación del conde. Su esposa Teresa no parece que merezca consideración aparte en vida de Enrique, dado que no jugó un papel de primer protagonista en las actividades gubernativas y militares del condado mientras vivió su esposo.

Alfonso VI entrega el gobierno del territorio portugalense bajo juramento de vasallaje a Enrique de Borgoña, esposo de su hija bastarda Teresa, hacia el año $1095^{15}$. La naturaleza del acto, tanto en el hecho de la entrega como en el de la aceptación, no aparece muy clara. En todo caso, se trata de una encomienda. Ciertamente, el hecho de que tal encomienda fuese hecha a título hereditario podía llegar a condicionar con el tiempo la naturaleza de la misma, como de hecho sucedería, pero en principio no se ve que los interesados actuaran en ningún momento con intención de modificar el statu quo de la condición condal de su territorio ${ }^{16}$.

Por parte del conde no parece seriamente discutible que dejara de comportarse como un fiel vasallo dentro del reino/imperio ${ }^{17}$; por lo menos, hasta la

14 Cf. para Portugal, especialmente, MATTOSO, José: en varios estudios, entre los que destaco: Ricos-Homens, Infançôes e Cavaleiros, a nobreza medieval portuguesa nos séculos XI e XII, Lisboa, 1982. Para la España cristiana en general, MOXÓ y ORTIZ DE VILLAJOS, Salvador de: Repoblación y Sociedad en la España Cristiana Medieval, Madrid, Rialp, 1979. Más concretamente sobre la organización social del espacio resultan interesantes las reflexiones y estudios de GARCÍA DE CORTÁzAR, José Ángel, Portela, Ermelindo; CABrera, Emilio; GonzÁlez, Manuel; y LÓPEZ DE CoCA, José E.: Organización social del espacio en la España medieval. La corona de Castilla en los siglos VIII a XV, Barcelona, Ariel, 1985. Aunque Portugal queda fuera de consideración, no faltan alusiones a la zona portuguesa en algunas de estas aportaciones. Véase asimismo el estudio exhaustivo para el área territorial de León de SÁnChez BAdiola, Juan José, El Territorio de León en la Edad Media. Poblamiento, organización del espacio y estructura social (siglos IX-XIII), 2 vols., Serie Tesis Doctorales, Universidad de León, León 2004, con abundante bibliografía.

15 La fecha de 1095 no es del todo segura, sino la más probable. En todo caso, se da como seguro que en 1096 Enrique tenía ya la responsabilidad, no compartida con Raimundo, del condado. Cf. MatToso, José (Dir.): História de Portugal, II: A Monarquia Feudal(1096-1480), Lisboa, Editorial Estampa, 1994, p. 32. El propio Mattoso es autor de los trabajos que ocupan las páginas 11-309 de este segundo volumen y que corresponden a la historia de los años 1096-1325.

16 GaUtier Dalche, Jean: «Un échec de la principauté: le cas des royaumes occidentaux de la péninsule ibérique», separata de Les principautés au Moyen Âge: Actes Congrès Société des historiens médiévistes de l'Enseignement Supérieur Public, Bordaux, 1979, p. 14, califica el condado de "principauté autonome».

17 Uso el término con referencia a León y Castilla, para destacar su principalidad en el territorio hispano. 
muerte de Alfonso VI en 1109, como matiza Oliveira Marques ${ }^{18}$, aunque António Cruz dé por admitida la opinión de que Enrique luchó infructuosamente por la independencia ${ }^{19}$, quizá siguiendo la estela de Damião Peres, para quien el proceso independentista obedece a dos factores fundamentales: el particularismo portugués que se manifiesta desde mediados del siglo XI y la ambición de Enrique $^{20}$. Y en cuanto a la ampliación del territorio del condado, especialmente por las conquistas hechas a los musulmanes, no tenía por qué modificar ese statu quo. En último término, la ampliación era para el reino/imperio.

Hay un dato, acorde con la ambición de Enrique, que se interpreta a favor de una tendencia de rebeldía con tintes de independencia. Me refiero a la actuación del conde portugués en la crisis sucesoria de Castilla y León, iniciada unos años antes de la muerte de Alfonso VI, cuando éste decidió designar sucesor a su hijo ilegítimo Sancho. Se trata, en concreto, del pacto sucesorio ya mencionado. La pareja Urraca-Raimundo, que gobernaba Galicia, aspiraba al trono por sucesión natural, mientras que la pareja Teresa-Enrique no quería desaprovechar la ocasión de reafirmar y ampliar su ámbito de poder. La situación habría dado lugar a una especie de pacto sucesorio, por el cual Teresa y Enrique apoyarían las pretensiones de Raimundo y Urraca a cambio de sumar Toledo o Galicia a su condado. De hecho, a fin de cuentas, no hubo tiempo suficiente para que fructificara el pacto, si es que realmente existió, ya que Raimundo muere en 1107, Sancho en 1108 y Alfonso VI en 1109. Pero no veo que a través de estas luchas de poder se esté favoreciendo de alguna forma, intencionada o no, la independencia de Portugal.

Urraca hereda el reino. En las luchas que se entablaron entre los nobles a partir del casamiento rápido de Urraca con Alfonso I de Aragón, el Batallador, Enrique juega al lado de unos y otros sin comprometerse a fondo con ninguno. El conde muestra en este juego su ambición sobre tierras de fuera del condado portugalense. Sus pactos con unos y otros, con Urraca y con Alfonso I de Aragón, o contra ambos, no se pueden mezclar con intento alguno de independencia por parte de Enrique respecto a Portugal. No está aquí en juego el futuro del condado, sino el poder en el reino/imperio. Valga como ejemplo de los movimientos en busca del poder en el ámbito del reino/imperio, sin tener en cuenta el condado de Portugal, y con todas las cautelas por las dudas de redacción, fecha e intención de su elaboración, un documento, procedente del Archivo del

18 Oliveira Marques, António H. de: História de Portugal, vol. I, Lisboa, 1985, p. 74.

19 CRUZ, António: «A situação política em Portugal em 1179", en $8^{\circ}$ centenário do reconbecimento de Portugal pela Santa Sé, Lisboa, Academia Portuguesa da História, 1979, p. 30: «Admite-se que o Conde D. Henrique tenha morrido no ano de 1112, sem haver conseguido uma efectiva, reconhecida e respeitada autonomia para o Condado Portucalense, como era da sua vontade e pela qual tanto lutou, nem tão-pouco ter alcançado, associada a ela ou a servir-lhe de fundamento, a emancipação da Igreja portuguesa».

20 Peres, Damião, (Dir.): Historia de Portugal, vol. I, Sétima Parte: A Reconquista Cristâ, Barcelos (a cargo de Damião Peres), Portucalense Editora, 1928, p. 487-488. 
monasterio de San Juan de la Peña y conservado en el Archivo Histórico Nacional, referente a un proyectado reparto del reino de León y Castilla entre Urraca y el conde Enrique, como solución al problema sucesorio que se había planteado a la muerte de Alfonso VI ${ }^{21}$.

Enrique muere en 1112 estando en buena armonía con Urraca, ya separada del rey de Aragón por sentencia papal de nulidad matrimonial por razón de parentesco en grado prohibido, promulgada por el arzobispo de Toledo y primado de Hispania.

Mi conclusión es que a través de las actuaciones más significativas de Enrique, tanto en sus luchas contra los moros como en la administración de su condado y en las relaciones con el resto de Castilla y León, no se percibe que en su juego político se marque una meta más allá de la de proteger, afirmar y ampliar su condado y su poder en el mismo, con la autonomía máxima que le era posible dentro de la condición de feudo hereditario de su territorio. No encuentro datos que permitan lucubrar con fundamento real sobre una posible intencionalidad de afirmación nacional ni siquiera pre-nacional por parte de Enrique y su entorno frente a Castilla y León. Sus actuaciones se pueden entender y explicar perfectamente dentro del ámbito propio que le correspondía como gobernador del condado por encargo a perpetuidad y hereditario de su suegro Alfonso VI de Castilla y León, y bajo el juramento de vasallaje y en el marco de sus ambiciones políticas personales.

Teresa, de su lado, a partir de la muerte de Enrique, se comportó como condesa, hija del difunto rey/emperador Alfonso VI y hermana de Urraca, reina. Su actuación ocasional de enfrentamiento con Urraca no tenía que ver tanto con el condado de Portugal como con el condado de Teresa misma, en el sentido de mirar por, y ampliar, su poder hacia Galicia, territorio que en ese momento, muerto Raimundo y siendo Urraca reina de Castilla y León, quedaba en manos de las ambiciones de los magnates gallegos. En última instancia, Teresa presta homenaje a su hermana Urraca y, a la muerte de ésta en 1126, presta vasallaje a su sobrino Alfonso Raimúndez, quien subiría al trono con el nombre de Alfonso VII.

Pero para entonces, aprovechando la ausencia de un gobierno sólido en el reino/imperio, se había ido formando en el entorno de Teresa (quien con su mirada hacia Galicia ponía en peligro la autonomía del condado portugalense), y a espaldas suyas, un grupo de nobles portuguesistas que arropaban a su hijo, Alfonso Enríquez. La ocasión era, en efecto, propicia, no sólo para fortalecer el condado de Portugal contra el alejamiento de Teresa y contra las convulsiones en el reino/imperio, sino incluso para ir más allá y caminar hacia un reino propio. Pero hasta ese momento no veo que aparezca en el horizonte político por-

21 Lo analiza y transcribe, junto a otro documento, LACARRA, José María: Colonización, parias, repoblación y otros estudios, IX: Dos documentos interesantes para la historia de Portugal, Zaragoza, 1981, pp. 209-219 (análisis); pp. 222-224 (edición). 
tugués movimiento alguno serio orientado hacia la formación de un reino independiente, lo cual, por otra parte, tampoco hubiera tenido nada de extraño dentro de la pluralidad monárquica hispana del momento.

Si queremos ver las cosas desde la perspectiva del principio metafísico clásico: del esse ad posse valet illatio, parece posible decir ahora, cuando se ha constatado la illatio, que las circunstancias, que vemos recogidas por los historiadores en favor de la independencia portuguesa desde la formación de una nobleza local, pasando asimismo por el condado de Enrique y Teresa, llevaban hacia la constitución de una comunidad soberana, hasta donde cabe hablar de soberanía en ese tiempo, a la formación de un reino independiente, puesto que de hecho Portugal llegó a serlo. Diremos que fue, luego pudo ser.

No me parece, sin embargo, que sea ese el camino adecuado para analizar los hechos. Creo que es más propio examinar los acontecimientos desde la perspectiva del principio metafísico opuesto al antes indicado: del posse ad esse non valet illatio. Vistos así los hechos, no podemos llegar sin más a la conclusión expuesta. El panorama es otro. Se constata, en efecto, la formación más o menos paulatina de un conjunto humano que se desarrolla y crece dentro de un cauce común y que va asumiendo sus peculiaridades respecto de otros conjuntos vecinos, pero dentro de un mismo reino. Desde este punto de vista, considero que la regionalización de la tierra y la estructuración social, a las que llegó Portugal, no fueron de por si factores decisivos hacia la independencia. Es más, como tal, creo que no se trata de factores muy distintos de los que se dieron en otras regiones (pongo, por caso, el condado gallego), en las que dichos factores no llegaron a ser eficaces en esa dirección ${ }^{22}$. De ahí que, situado en el tiempo real de la evolución de los hechos, estimo que no se puede afirmar que la regionalización y el acrecentamiento del poder de la nobleza del territorio, especialmente de los infanzones, así como las actuaciones condales de afirmación de poder de Enrique y Teresa, constituyesen pasos directos hacia la independencia, ni en si mismos como sucesos ni en la intención de los protagonistas de los mismos $^{23}$. Fueron, eso sí, circunstancias que, llegado el momento, es decir, cuando los poderes fácticos del territorio portugalense fueron conscientes de que se les abría el camino hacia la constitución de un reino y decidieron dar pasos hacia ella, resultaron favorables a la resolución positiva de la misma.

22 Cf. MatToso, José, (Dir.): História de Portugal, II..., p. 14. Mattoso, discurriendo sobre la formación de la nacionalidad portuguesa, recoge a su modo la idea referida en el texto. Afirma que el proceso portugués de formación de la nacionalidad es «semelhante ao de outras regiões do espaço cristão peninsular, embora em algumas destas não tenha conduzido à formação de unidades políticas definitivamente autónomas, como aconteceu precisamente com a Galiza».

23 ReILly, Bernard. F.: Las Españas medievales, trad. De José Manuel Álvarez Flórez, Barcelona, Ediciones Península, 1996, p. 154, afirma a este respecto que «los planes de Enrique y Teresa eran acceder ellos mismos al trono del reino de León-Castilla más que crear un nuevo reino desconocido hasta entonces». 


\section{LA IGLESIA DE BRAGA}

En cuanto al factor eclesiástico, la iglesia local no mostraba tendencia alguna independentista en ese tiempo. La atención toda de los historiadores se concentra en la sede bracarense, lo que nada tiene de extraño, dada su trayectoria histórica. Braga había sido desde los primeros tiempos de la implantación del cristianismo en la Península Ibérica la sede principal de Galicia y una de las primeras de la Hispania cristiana, junto a Cartagena, Mérida, Sevilla y Tarragona ${ }^{24}$. Una vez restaurada, año 1070, esperaba recobrar su antigua dignidad de sede metropolitana, que suponía ciertos poderes sobre determinadas diócesis de su entorno geográfico llamadas sufragáneas, tal como le correspondía conforme a las premisas fijadas en la restauración de las sedes ${ }^{25}$. Pero esto no sucedió.

Sin embargo, conquistada Toledo en 1085 , en pocos años se restaura al máximo nivel como metropolitana de todas las sedes hispanas. Para entonces no se había restaurado todavía ninguna que anteriormente hubiera sido metropolitana excepto Braga, no reconocida como tal. Además, a Toledo se le añade la dignidad de ser sede primada de España, institución novedosa que se instaura con la reforma gregoriana como instrumento para encauzar los ideales de reforma. Así lo decidió Urbano II el 15 de octubre de 1088 por la Bula Cunctis sanctorum $^{26}$. La institución del primado toledano tuvo gran resonancia, hasta el

24 Cf. Mansilla Reoyo, Demetrio: «Orígenes de la organización metropolitana en la iglesia española», en Hispania Sacra, 12 (1959), pp. 275-281

25 La verdad es que este criterio de que las sedes que habían sido metropolitanas, una vez reconquistadas, recobraban automáticamente su dignidad y su derecho, que recogen historiadores como Pierre David (Études historiques sur la Galice et le Portugal du VI au XII siècle, Paris, Institut Français au Portugal, 1947, pp. 121 y 456), se aplicó a la conveniencia del momento. De hecho, fuera de Toledo, solamente Tarragona recobró con normalidad la dignidad metropolitana. Braga la consiguió con esfuerzo después de larga espera, Mérida no lo conseguiría ya nunca, Santiago de Compostela, que no había sido siquiera sede episcopal, pasaría a ser metropolitana en lugar de Mérida, y Sevilla no estaba en juego en ese tiempo. MARQUES, José: «O problema da «primazia arquiepiscopal das Espanhas: Toledo ou Braga?»«, en Studium Dilectum. Colectânea de Homenagem ao Prof. Doutor Justino Mendes de Almeida, Lisboa, Academia Portuguesa da História, 1999, pp. 199222 , en concreto, en nota 20, p. 207, hace el contrapunto a la posición que aquí expreso y que expuse en mi artículo «Braga y Toledo en la polémica primacial», en IX Centenário da Dedicaşão da Sé de Braga. Congresso Internacional. Actas, vol. II/1: A Catedral de Braga na História e na Arte (séculos XII-XIX), Braga, Universidade Católica Portuguesa, 1990, nota 14, p. 18; y en Hispania, 50 (1990), nota 15, p. 9. En realidad, el contrapunto es leve. Para José Marques se trata de una obligación no cumplida, para mi de un criterio no siempre seguido.

26 Bula «Cunctis sanctorum» de Urbano II de 15 de octubre de 1088: «Primatem te universi Hispaniarum presules respicient et ad te, si quid inter eos questione dignum exortum fuerit, referent, salva tamen Romane auctoritate ecclesie et metropolitanorum privilegiis singulorum... Illarum autem civitatum dieceses que, saracenis invadentibus, metropolitanos proprios perdiderunt, vestre ditioni eo tenore subicimus, ut quoad sine propiriis extiterint metropolitanis, tibi ut proprio debeant subiacere» = «Todos los obispos de las Españas te tomarán por primado y acudirán a ti si surgiere entre ellos algún problema de importancia, dejando a salvo la autoridad de la iglesia de 
punto de que Carl Erdmann la considera «o grande e decisivo acontecimento da história eclesiástica peninsular do século $\mathrm{XI}^{27}$. En diversos periodos de tiempo, el arzobispo de Toledo unió a estas dignidades la de legado papal.

Braga lucha en primer lugar por recobrar la dignidad metropolitana. En esa lucha estaban en cuestión intereses eclesiásticos y también civiles del territorio portugalense. En principio, se enfrenta a los intereses de Toledo, que no sólo representaba los del reino/imperio, sino también y sobre todo los del papado; pero luego deberá enfrentarse asimismo a las ambiciones de Santiago de Compostela y Galicia, con Diego Gelmírez a la cabeza, el cual ansiaba obtener para su sede la dignidad metropolitana, substituyendo a Braga en la Galicia eclesiástica. En torno al 1103, el obispo Giraldo alcanza el reconocimiento de sede metropolitana para Braga, aunque un poco a medias, ya que se queda con el título de obispo. Tres de sus sufragáneas, Coimbra, Viseu y Lamego ${ }^{28}$, eran diócesis de la antigua sede metropolitana de Mérida. En 1114 el obispo de Braga Mauricio consigue el título de arzobispo y regulariza la condición de sede metropolitana para Braga. Diego Gelmírez, que maniobraba para conseguir esa condición para su sede compostelana, aprovechando momentos de debilidad de la sede bracarense, intentó transferir la dignidad metropolitana de Braga a Santiago de Compostela, pero sin éxito. Sin embargo, su amigo el papa Calixto II sí accedió en 1120 a concederle los derechos metropolitanos de Mérida, diócesis que quedó definitivamente sin restaurar, después de un intento en 1234, hecho fracasar hábilmente por el arzobispo compostelano Bernardo II

Roma y las prerrogativas de cada uno de los metropolitanos... Ahora bien, sometemos a vuestra jurisdicción las diócesis de las ciudades que perdieron a sus metropolitanos por la invasión de los sarracenos, con el tenor siguiente, que mientras estén sin sus metropolitanos se sometan a ti como a metropolitano propio» (MANSILla ReOYo, Demetrio: La documentación pontificia basta Inocencio III (965-1216), Roma, Instituto Español de Estudios Eclesiásticos, 1955, doc. 27, p. 44. Dado que el latín hoy es un idioma poco o apenas conocido, incluso por investigadores y estudiosos medievalistas, me ha parecido oportuno traducir los textos latinos citados.

27 ERdmann, Carl: O papado..., p. 9.

28 La pertenencia de Coimbra a Braga no estaba bien aclarada y, desde luego, no era pacífica. En 1109, cuando Mauricio pasó de la sede de Coimbra a la de Braga y le sucedió en Coimbra Gonzalo, este fue consagrado por el arzobispo de Toledo Bernardo, a quien prestó obediencia. Después consultó a Roma sobre a quién debía sumisión. El papa Pascual II se inclinó en principio por su pertenencia a Braga; pero luego, en el concilio de Burgos de 1117, presidido por el cardenal legado Boso, se discutió la cuestión y se resolvió la duda con el razonamiento de que Coimbra pertenecía a Mérida y, en consecuencia, a Toledo, mientras Mérida no fuera restaurada. En 1120 pasa a depender de Santiago de Compostela por decisión del papa Calixto II; en 1125 el papa Honorio II la pone bajo su protección, que renueva el papa Inocencio II en 1135. En 1162, el obispo Miguel Pais Salomão prestó obediencia al arzobispo de Braga, que era Juan Peculiar; y lo mismo hicieron sus sucesores. Sobre las vicisitudes de la sede conimbricense, Cf. Rodrigues, Manuel Augusto (Dir.): Livro Preto. Cartulario da Sé de Coimbra, Coimbra, Arquivo da Universidade de Coimbra, 1999, pp. CLXIX-CLXXXV de la introducción, a cargo de Manuel Augusto RODRIGUES, con notación de los documentos relativos al tema contenidos en el mismo Livro Preto. En cuanto a Viseu y Lamego eran ciudades episcopales aún no restauradas. 
(1224-1240), precisamente el encargado de llevar a efecto la restauración. Con estas concesiones, las sedes metropolitanas de Braga y Santiago de Compostela cruzaron en buena parte sus sedes sufragáneas. Por ejemplo, Braga tuvo por sufragáneas las diócesis gallegas de Mondoñedo, Lugo, Orense y Tuy, y la leonesa de Astorga; mientras que Santiago de Compostela tuvo como sufragáneas las diócesis portuguesas de Lamego, Idanha-Guarda, Lisboa y Évora. Esta correspondencia cruzada se observa igualmente en muchas parroquias. Por ejemplo, las parroquias de la tierra de Ribacoa pertenecieron a la diócesis de Ciudad Rodrigo hasta el año 1403, a pesar de que en el acuerdo de Alcañices (12-IX1297) Fernando IV de Castilla y León desistía de Ribacoa a favor del rey portugués. Se podrían poner otros muchos ejemplos. En realidad, pasa lo mismo o algo parecido en todas las zonas fronterizas ${ }^{29}$. Se pone bien de manifiesto que los límites jurisdiccionales eclesiásticos no van en paralelo a los límites civiles ${ }^{30}$.

Obtenido el reconocimiento de la dignidad metropolitana, quedaba pendiente la sumisión a la primacía toledana, donde se ponía en juego el papel de cada sede, fuera metropolitana o sufragánea, dentro del ámbito del reino/imperio, en el que Toledo en esos momentos era protagonista. Es cierto que en la concesión de la primacía a Toledo se indica que en el ejercicio de la misma deberán quedar a salvo las prerrogativas de los metropolitanos, pero no dejaba de ser un poder superior con exigencia de sumisión y muestra de plusvalía, ambas cosas de difícil aceptación por parte de otras sedes, máxime si su dignidad episcopal venía de antiguo, como en el caso de Braga, o si se alegaba mezcla de méritos y ambición, al estilo Gelmírez. Si a la dignidad primacial se le añade la autoridad derivada de la legacía papal que también ostentó el primado toledano en varias temporadas, los motivos para el rechazo se hacían más evidentes, de modo que las intervenciones del arzobispo toledano por razón de cualquiera de sus cargos se interpretaban como una injerencia no deseada y una muestra de prepotencia indebida. Es cierto que la legacía no debía crear en principio problema alguno, pues se entendía bien que su designación fuera de libre elección papal. No obstante, el hecho de que se acumulase en Toledo todo el poder eclesiástico no favorecía la concordia entre las sedes.

En cualquier caso, en ninguna de estas disputas de Braga con Toledo y con Santiago de Compostela estuvo en juego, en principio, la independencia portuguesa. No lo estuvo por parte de la Iglesia de Braga, sede principal del territorio portugalense, cuyo interés se centraba básicamente en obtener del papado la condición de sede metropolitana, dignidad que no se le había reconocido en

29 GARCía Oro, José: «Señorío y nobleza. Galicia en la Baja Edad Media», en Liceo Franciscano, $2^{a}$ época, nn. 88-90 (1977), p. 87, destaca los especiales problemas fronterizos de la diócesis de Tuy, que vivió «con más intensidad los comunes problemas de las otras iglesias gallegas».

30 Cf. Mansilla ReOYo, Demetrio: «Disputas diocesanas entre Toledo, Braga y Compostela en los siglos XII al XV», en Antológica Annua, 3 (1955), pp. 89-143; "Orígenes...», pp. 255-290; «Formación de la provincia bracarense después de la invasión árabe, en Hispania Sacra, 14 (1961), pp. 5-25. 
el momento de su restauración, y que su primer obispo, D. Pedro, comenzó a reclamar con todo empeño hacia 1089-1090, bastantes años después de su designación en 1070 por García, rey de Galicia ${ }^{31}$. Conseguida la categoría de metropolitana, reconocida por el papa Pascual II (1099-1118) al inicio de su pontificado, siendo obispo de Braga D. Geraldo, elegido o nominado en 1099, no en $1096^{32}$, Braga buscó también ser liberada de la sujeción a la primacía toledana, no para ser ella la primada portuguesa, gallega o hispana, sino porque la consideraba una intromisión en sus derechos de metropolitana, entendiendo incluso que a Braga le asistía mejor fundamento que a Toledo para ser sede primada de la iglesia hispana ${ }^{33}$.

Se tiende a confundir y en consecuencia a tratar per modum unius la dignidad metropolitana y la primacía, lo cual no es acertado y puede inducir a errores de interpretación ${ }^{34}$. Cuando Braga obtiene la dignidad de sede metropolitana, deja de luchar por ella como tal. Sin embargo, mantiene viva la polémica primacial durante largos años, aunque a partir del reconocimiento del reino de Portugal por la Santa Sede en 1179 las disputas pierden virulencia. El arzobispo toledano Rodrigo Jiménez de Rada (1209-1247) quiso reactivar la operatividad del privilegio primacial en el concilio IV de Letrán (1215), sin conseguir su propósito y la polémica pasó a ser un asunto de simple retórica teológico-jurídica ${ }^{35}$.

De todas formas, en tiempos del conde Enrique no había caso. La sede toledana ejercía sin mayor discusión la primacía y la representación del papado en la Península. Rivera Recio va más lejos al afirmar que no hay prueba alguna de desacato a la primacía de Toledo hasta 1143 , siendo Braga la primera en rebelarse ${ }^{36}$.

31 ERdmann, Carl: O papado..., pp.11-12; Costa, Avelino de Jesus da, O bispo..., p. 243.

32 Se ha venido indicando la fecha de 1096, pero Avelino de Jesús da Costa la posterga hasta 1099: A vacancia da Sé de Braga e o episcopado de S. Geraldo (1092-1108), Braga, [s.n.], 1991.

33 Todavía puede leerse en el frontispicio de la catedral bracarense la anotación de Primas Hispaniarum. Y se ve con normalidad la aplicación del término primacial a la iglesia de Braga, comenzando por José A. Ferreira en el título de su celebrada obra Fastos episcopaes da Igreja Primacial de Braga (sec. III - sec. XX), Famalição, Mitra Bracarense, 1928-1935.

34 Es una confusión bastante generalizada, pero pondré sólo dos ejemplos. OliveIra MARQues, António H.: en su História de Portugal, vol.I: Das origens ao renascimento, Lisboa, Palas Editores, $12^{\mathrm{a}}$ edición, 1985, p. 81, habla del "primado de Braga», cuando en realidad está tratando del reconocimiento de la dignidad metropolitana: «Alguns anos mais tarde, o arcebispo Geraldo deu novo passo em frente, conseguindo que o mesmo papa lhe reconhecesse o primado». MARTín Rodríguez, José L.: en La Península en la Edad Media, Barcelona, Editorial Teide, 1976, p. 363 , cae en la misma confusión: «Nombrado conde de Portugal, Enrique comprendió inmediatamente el interés que para el futuro de sus dominios tenía la pugna eclesiástica y logró de Roma el reconocimiento de Braga como sede primada de las diócesis gallegas y portuguesas».

35 Razono más detenidamente este punto en mi artículo «Braga y Toledo en la polémica primacial», en Hispania, 50 (1990), pp. 29-35; y en IX Centenário da Dedicaşão da Sé de Braga. Congresso Internacional. Actas, vol. II/1: A Catedral de Braga na História e na Arte (séculos XII-XIX), Braga, Universidade Católica Portuguesa, 1990, pp. 37-43.

36 Rivera Recio, Juan F., La Iglesia de Toledo en el siglo XII (1086-1208), Roma, Instituto Español de Historia Eclesiástica, 1966, p.387. 
En realidad, durante largo tiempo el poder de Toledo fue indiscutible en toda la Península, lo cual no quiere decir que ese poder fuera aceptado de buena gana. Braga tenía razón para sentirse ofendida en su dignidad desde el momento mismo de su restauración en 1070 por no haberle sido reconocida la dignidad metropolitana desde el principio. Recordemos, además, que habría sido la primera. De otra parte, no era sólo Braga la que deseaba desvincularse del dominio metropolitano, primacial y ocasionalmente legatino de Toledo, también las otras sedes metropolitanas, Santiago de Compostela, desde que lo fue, y, más tarde, Tarragona, lucharon contra el poder concedido a Toledo ${ }^{37}$; e incluso otras diócesis importantes del reino de Castilla y León, como Burgos, León y Oviedo, que, por cierto, consiguieron depender directamente del papado: Burgos en 1095 por bula de Urbano II, León y Oviedo en 1105 por bulas de Pascual II. Su exención duró hasta el concordato de 1851, cuando se llevó a cabo una nueva demarcación de provincias eclesiásticas, salvo un paréntesis de treinta y tres años para León, entre 1121-1154, tiempo en que dejó de ser exento, al menos de iure e $^{38}$.

Se trata, pues, de luchas de poder entre sedes episcopales importantes, fuera por su pasado, por su presente, o por ambas cosas a un tiempo. No hay razones para una interpretación distinta en el caso concreto de Braga. Y no es cuestión de oponer los intereses de Braga y Portugal a los de Toledo y Castilla y León, como si tuvieran que ser necesariamente contrarios, y sólo en este supuesto y en esta dirección. Es, sin embargo, la hipótesis a la que se apunta, con otros muchos, Miguel de Oliveira, al identificar los intereses de Toledo con los de León y Castilla y contraponerlos a los intereses de Braga, intereses que identifica con las aspiraciones de los portugueses:

$\mathrm{Na}$ sé bracarense, D. Geraldo, longe de favorecer os interesses de Toledo, idênticos aos de Leão e Castela, reivindicou a autonomia eclesiástica da diocese, servindo as aspirações dos portugueses governados por D. Henrique ${ }^{39}$.

37 Además de los trabajos ya citados de Carl Erdmann, Pierre David, Juan F. Rivera Recio y Demetrio Mansilla Reoyo, en los que se ocupan ampliamente de la polémica primacial, cf. MARQUES, José, «O problema da «primazia arquiepiscopal das Espanhas: Toledo ou Braga?»«, en Studium Dilectum. Colectânea de Homenagem ao Prof. Doutor Justino Mendes de Almeida, Lisboa, Academia Portuguesa da História, 1999, pp. 199-222; Soto RÁBANOS, José Mª ., «Braga y Toledo en la polémica primacial», en IX Centenário da Dedicaşão da Sé de Braga. Congresso Internacional. Actas, vol. II/1: A Catedral de Braga na História e na Arte (séculos XII-XIX), Braga, Universidade Católica Portuguesa, 1990, p. 15-46, y en Hispania, 50 (1990), pp. 5-37; FEIGÉ, Peter., «La primacía de Toledo y la libertad de las demás metrópolis de España. El ejemplo de Braga», en La introducción del Císter en España y Portugal, Burgos, 1991, pp. 63-132.

38 Remito para estas tres diócesis al Diccionario de Historia Eclesiástica de España, bajo la dirección de Quintín ALdeA, Tomás MARín, José Vives, vol. I, pp. 290-295: Burgos, a cargo de Demetrio Mansilla ReOYO; vol. II, pp. 1278-1286: León, a cargo de José M., FernándeZ CATÓN; vol. III, pp. 1851-1855: Oviedo, a cargo de José L. GonZÁleZ Novalín. Con la bibliografía citada en cada caso.

39 Oliveira, Miguel de., História Eclesiástica de Portugal, 4ª ed., Lisboa, União Gráfica, 1968, p. 110. 
Será más tarde cuando a esta lucha meramente de poderío eclesiástico, en la que Braga se las tiene que ver con una sede políticamente mucho más importante en la doble vertiente que entonces conllevaba de poder espiritual y temporal, se una, por la acción de los poderes civiles especialmente, el interés por disponer de una organización eclesial de carácter nacionalista que gire en torno a Braga como primera cabeza, y que comprenda a las otras diócesis portuguesas y a las instituciones religiosas en general. Este objetivo se consiguió en parte al constituirse Portugal en reino independiente, pero no del todo hasta finales del siglo XIV. En realidad, esa lucha no parece que fuera posible en el estado de la situación política del momento, puesto que cuando se refunda la iglesia bracarense aún no se ha iniciado, al menos de forma clara y decidida, el camino hacia la independencia.

\section{ALFONSO ENRÍQUEZ. DECISIÓN DE FORMAR UN REINO INDEPENDIENTE.}

En mi opinión, cuando se empieza realmente a caminar hacia la independencia es cuando emerge la figura de Alfonso Enríquez, en momentos de gran debilidad en el reino/imperio castellano-leonés, en el río revuelto de alianzas y desalianzas, en tiempos de fuerte y prolongada crisis de poder. Sin pretender hacer de profeta de futuribles, estimo que si Alfonso Enríquez hubiera visto alguna oportunidad sólida de ascender al trono castellano-leonés, es muy probable que nadie en Portugal hubiera emprendido el camino hacia la independencia y que, consecuentemente, Portugal no hubiera pasado a ser reino en ese tiempo, pese a los antecedentes, y sin prejuzgar su posible futuro a medio o largo plazo ${ }^{40}$.

Lo dicho no quiere decir que me incline hacia la opinión de la independencia por azar, hacia la llamada «teoría del acaso histórico» ${ }^{41}$. Estimo que Portugal no se encontró con la independencia; que no llegó a ser reino de la noche a la mañana. Desde que es hecho condado gratuitamente hasta que consigue ser reino con todos los honores, en ese proceso versus León y Castilla, se conjugan una serie de factores, en los que intervienen fuerzas políticas y religiosas. Llegado el momento, los poderes fácticos lo aprovecharon, lucharon con denuedo por la independencia, la consiguieron y supieron consolidarla de manera definitiva a lo largo de varios siglos. Constituye, por ello, realmente, como señala

40 Reilly, Bernard F.: Las Españas..., p. 155, señala la indecisión primera de Alfonso Enríquez: «Con Alfonso Henriques (1128-1185) surgió un reino de Portugal claramente independiente, aunque él mismo vacilase también sobre el camino a seguir».

41 SOUSA SOARES, Torquato: Reflexões sobre a origem e a formação de Portugal, t. I, Coimbra, Faculdade de Letras da Universidade de Coimbra, 1962, en el prólogo (pp. 15-28), tras un primer planteamiento, dedica varias páginas a criticar respetuosa y enérgicamente la opinión de Albornoz sobre el nacimiento «fortuito y casual» de Portugal. 
Maria João Violante Branco ${ }^{42}$, un caso original en el contexto de los reinos peninsulares, ya que se trata del único ejemplo de escisión definitiva en el panorama de la dialéctica hispánica entre el imperio y los reinos, que se prolonga a lo largo de toda la edad media. En esa lucha, los nobles independentistas encontraron alguna ayuda de la iglesia local, de modo que se puede hablar de un cierto entramado político religioso, que no siempre caminó de consuno, pero que supo superar obstáculos políticos e ideológicos internos: entre el conde-rey Alfonso Enríquez y las propias iglesias locales, y externos: con León y Castilla y con el papado.

La primera batalla en el camino de la independencia portuguesa la gana Alfonso Enriquez frente a su madre y al favorito de ésta, el noble gallego Fernando Pérez de Trava. Su victoria en la batalla de São Mamede, en la zona de Guimarães, en 1128, afirmará de modo definitivo el poder de Alfonso Enriquez en el condado portugalense ${ }^{43}$. Teresa y Fernando se retiran a Galicia definitivamente. Y allí muere Teresa en 1130.

Las actuaciones político-diplomáticas y militares de Alfonso Enríquez a partir de la batalla de São Mamede, de la «primeira tarde portuguesa» como la intituló Acácio Lino en su panel de la batalla ${ }^{44}$, están marcadas ya con el sello de la voluntad de constituir un reino independiente, cuando menos al estilo de los otros reinos de Hispania. Por de pronto, Alfonso Enríquez y sus hombres se liberan de la tutela gallega, es decir, de los vínculos que unían los territorios portugueses a Galicia, y se enfrentan a sus propios retos. Prácticamente, hay unanimidad entre los investigadores que se ocupan del tema en reconocer la batalla de São Mamede como el primer paso verdaderamente relevante hacia la escisión de Portugal del reino de León ${ }^{45}$.

De 1128 a 1143 Alfonso Enríquez se afianza como líder de su espacio, que trata de proteger por el norte frente a Galicia, por el sur frente a las embestidas musulmanas y por el este frente a León y Castilla. A partir de 1131 traslada su residencia habitual de Guimarães a Coimbra, desde donde puede ejercer un mejor control del condado ${ }^{46}$. Por de pronto, consigue la colaboración de la clase noble portuguesa para su causa.

Se esfuerza por conseguir asimismo la colaboración de la iglesia local, que se hallaba entonces, en palabras de Erdmann, «em lamentável estado de des-

42 Violante Branco, Maria J.: «Portugal no reino...», p.568.

43 Defourneaux, Marcelin: Les français en Espagne aux XI et XII siècles, Paris, Presses universitaires de France, 1949, p. 207, considera la victoria de São Mamede «l'origine du véritable «coup d'état» qui, en 1128, mit fin à l'autorité qu'exerçaient Thérèse et son favori».

44 Panel incluido en el vol. I de la edición monumental de la História de Portugal, dirigida por Damião Peres y Eleutério CerdeIRA, Barcelos, Portucalense Editora, 1928, en la página anterior al Prefácio.

45 Cf. por todos, Violante BRanco, Maria J.: «Portugal no reino...», p. 596.

46 MAtToso, José: História..., pp. 64-69, detalla las grandes ventajas de fijar la residencia en Coimbra. 
composição» ${ }^{47}$. Para empezar, en la elección de nuevos obispos favorece a personas de su línea política. En el mismo año 1128 detiene la elección de D. Tello para la sede de Coimbra por haber sido persona de confianza del anterior obispo D. Gonzalo, que no se había mostrado portuguesista, y promueve al arcediano de Braga D. Bernardo, que sí parecía serlo. Al menos, prestó obediencia al arzobispo de Braga, Pelagio Méndez $^{48}$, lo que no fue óbice para que sostuviera varios pleitos con Braga, siendo arzobispo Juan Peculiar, así como con el obispo de Porto, D. Pedro Rabaldes, por cuestiones de derechos jurisdiccionales y económicos. En 1136 consigue situar en la sede de Porto a su protegido y aliado D. Juan Peculiar, a quien poco después, en 1138, promueve a la sede metropolitana de Braga. Además, da los primeros pasos para buscar el apoyo del papado.

Con relación a su primo Alfonso VII, de quien se sabe y reconoce vasallo, su actuación fue de distanciamiento con el menor ruido posible, buscando la armonía sin apenas cesiones en los momentos problemáticos, de lo que dan fe bastante el pacto de Tuy y la solución hallada a su dolorosa derrota de Badajoz. En cualquier caso, Alfonso Enríquez procura avanzar con una política de hechos consumados, siendo consciente de que el «emperador» cree tener otros problemas más urgentes frente a su imperio que los que él puede causarle. Me refiero especialmente a la situación creada en Aragón a la muerte de Alfonso I el Batallador (1134) y al poder alcanzado por Ramón Berenguer IV en Aragón-Barcelona a partir de 1137. Así, casi sensim sine sensu, llega a darse a si mismo el título de rey y consigue más tarde que Alfonso VII lo acepte como tal, sin ver en ello obstáculo al vasallaje ${ }^{49}$. En 1143, en Zamora, con la mediación del legado papal Guido de Vico, negocia un acuerdo por el cual Alfonso VII admite el título de rey para su primo Alfonso Enríquez con cláusulas de un cierto vasallaje $\mathrm{e}^{50}$.

Se puede afirmar que era un rey sui generis de un territorio no independiente o, si se quiere, independiente sólo hasta cierto punto. Apenas era rey, pues no tenía un reino propio; y, aunque él no lo quisiera ver así, era consciente de ello. Le faltaba el reconocimiento principal: el del papado, que lo liberara de otros vasallajes. C. Erdmann llama la atención sobre la importancia de las rela-

47 ERDMANN, Carl: O papado..., p. 34.

48 Costa, Avelino de Jesus da, (Ed.), Liber Fidei Sanctae Bracarensis Ecclesiae, Braga, Junta Distrital, 1965-1990, docs. 371 y 548. En ambos documentos se da noticia de la prestación de obediencia al arzobispo de Braga.

49 Mattoso, José: História..., p. 62, afirma que la adopción del título de rey (entre 11391140 ) es lo que «marca definitivamente a independência de Alfonso Enríquez». A renglón seguido, en pp. 62-64, expone detalles de la adopción del título, probablemente en un contexto guerrero, y razona la divergencia de posiciones del papado y del nuevo rey precisamente en el modo de adoptar el título, más fácil de entender por Alfonso VII, pese a ser el más afectado, que por el papado.

50 No se conserva el texto del llamado tratado de Zamora de 1143. Sabemos algo de su contenido por las referencias al mismo de otros documentos. Cf. FERREIRA, José A.: Fastos episcopaes da Igreja Primacial de Braga (sec. III - sec. XX), t. I, Famalição, Mitra Bracarense, 1928, p. 290; VerísSimo Serrão, Joaquim: História..., pp. 89-90. 
ciones entabladas con el papado en el proceso de independencia del reino portugués, entendiendo que:

A autoridade dos papas, mesmo quando êles se abstinham de intervir directamente nos negócios dos estados seculares, era tão grande que o reconhecimento ou não-reconhecimento dos pequenos estados formados na Península era para estes duma importância capital51.

\section{ALFONSO ENRÍQUEZ DE 1143 a 1179. LAS INSTITUCIONES ECLESIÁSTICAS LOCALES Y EL PAPADO}

De 1143 a 1179 Alfonso Enríquez acentúa sus incursiones en tierras de moros y conquista diversas plazas musulmanas importantes, como Santarem, Lisboa, Palmela, Alcácer do Sal y otras, con la ayuda especial de las órdenes militares. En primer lugar, de los templarios, con fines militares y de asentamiento; luego de los hospitalarios, con fines militares y de asistencia; más tarde de la orden de Calatrava (de Avis) y de la de Santiago, también con fines militares y de asentamiento. Estando ya seguro, por otra parte, de la colaboración del representante principal de la iglesia portuguesa, Juan Peculiar, arzobispo de Braga (1138-1175), el objetivo principal de Alfonso Enríquez será conseguir el reconocimiento de su persona como rey, y de Portugal como reino, por la Santa Sede, una vez hecho, unilateralmente, vasallo de la misma ${ }^{52}$. La Santa Sede venía solicitando desde tiempo atrás el vasallaje de Castilla y León sin conseguirlo; y en ese vasallaje entraba Portugal como parte. Sin embargo, ahora Portugal se ofrecía aparte como reino vasallo. Era sin duda una misión delicada para ambos poderes. Por su lado, Alfonso Enríquez contaba con el trabajo diplomático de varios personajes del clero local, muy en especial del ya mencionado Juan Peculiar ${ }^{53}$, y no escatimará esfuerzos en orden a la consecución del objetivo lo antes posible.

51 ERdmann, Carl: O Papado..., p. 4.

52 No voy a entrar en consideraciones sobre las relaciones, en general hostiles y de guerra intermitente, de Alfonso Enríquez, o mejor ya de Portugal, con Fernando II de León (1157-1188), hijo menor de Alfonso VII. Las relaciones eran ya de reino a reino, aunque el de León tenía y quería hacer valer su hegemonía, a pesar del auto-vasallaje portugués a la Santa Sede. Afectan sólo de manera indirecta al tema propuesto y alargarían en exceso este trabajo. De otra parte, tampoco veo interés en detenerme en aspectos expuestos ya suficientemente por los estudiosos del tema y sin apenas variación en sus análisis.

53 Fernández MARQues, Maria Alegria: «A viabilização de um reino», en SERrÃo, Joel y Oliveira Marques, António H. (Dir.): Nova História de Portugal, vol. III (Coordenação de CruZ Coelho, Maria Helena da y Carvalho Homem, Armando Luís de): Portugal em definiçãa de fronteiras (1096-1325). Do condado portucalense á crise do século XIV, Lisboa, Editorial Presenta, 1996, pp.23-37, lo ve también así. Concretamente, en p. 35 afirma: «O apoio do clero secular pode ser sintetizado numa só personagem, D. João Peculiar, o tenaz arcebispo de Braga». Pone a la par, como consejero del conde/rey, a S. Teotónio, primer prior de Santa Cruz de Coimbra: «A par dele, outro clérigo parece ter tido grande influência sobre o primeiro rei de Portugal: S. Teotónio» (ibid.). 
La Santa Sede se tomará el asunto con más calma. Acepta el ofrecimiento portugués de vasallaje, que entraba dentro de la ideología teocrática de la épo$\mathrm{Ca}^{54}$, pero no puede menos de estimar que reconocer a Portugal en ese momento como reino rompía la distribución del mapa peninsular y el esquema de actuación que estaba llevando a cabo en la Península, especialmente a través de sus legados y del primado toledano. A este razonamiento apunta Carl Erdmann, contra la opinión de que la Santa Sede tuvo un interés particular y una parte activa en la independencia portuguesa:

Ao contrário, a cúria, tendo sempre em vista na península ibérica o objectivo supremo da concentração de tôdas as fôrças para a luta com os infiéis, opôs-se, porisso mesmo, durante muito tempo, à criação dum Portugal independentess.

Insiste en la idea más adelante:

facto curioso mas fora de tôda dúvida, que a cúria se não mostrou absolutamente satisfeita com o enfeudamento de Portugal. O aumento de influência e prestígio daí derivado, aceitou-o-ela de boa mente. Mas o contúdo político de tôda a acção contrariava a política espanhola seguida então pela cúria com bastannte coêrencia ${ }^{56}$

Portugal significaba poco para el papado por entonces. Entre los historiadores se acepta sin discusión que la relación de la iglesia portuguesa y del poder civil local con Roma hasta 1138, con Alfonso Enríquez consolidado ya en su liderazgo y Juan Peculiar, su protegido, como arzobispo de Braga, había sido escasa y no institucionalizada. Esa escasa relación se había llevado por cauces más bien personales y concentrados en la sede bracarense. Recordemos las actuaciones de los obispos Pedro, Giraldo, Mauricio y Pelagio Méndez, con sus luces y sus sombras y, a fin de cuentas, más sombras que luces ${ }^{57}$. Justamente, Carl Erdmann atribuye la situación de precariedad de la iglesia portuguesa en ese tiempo a la falta de contacto directo con Roma y reconoce a Alfonso Enrí-

54 Nobre Veloso, Maria Teresa, D.Afonso II ..., trata en el capítulo II de «a supremacia do papado medieval: ascensão e consolidação» y dedica el punto tercero a «as manifestações da teocracia papal na Península Ibérica» (pp. 22-29), donde recoge brevemente las actuaciones principales: las cuestiones litúrgicas, las conquistas a los infieles, la unidad de los pueblos hispanos en la autoridad papal.

55 ERdmanN, Carl, 0 papado..., p. 4.

56 Ibid., p. 48.

57 Las sombras las protagonizaron los obispos Pedro y Mauricio, que fueron depuestos. Pedro por acudir al (anti)papa Clemente III para obtener la dignidad metropolitana, y Mauricio por enfrentarse primero al papa Pascual II en apoyo del emperador Enrique V y luego al papa Gelasio II, aceptando la designación papal de manos del emperador y convirtiéndose en (anti)papa con el nombre de Gregorio VIII. Sobre Pedro, cf. Costa, Avelino de Jesus da, D. Pedro...; sobre Mauricio, ERdmanN, Carl, «Mauritius Burdinus (Gregor VIII.)», en Quellen und Forschungen aus italienischen Archiven und Bibliotheken 19 (1927), pp. 205-261. 
quez el mérito de reanimarla, señalando como causa a destacar el establecimiento de contactos directos entre Portugal y el papado ${ }^{58}$. Poco a poco se hizo presente ante la curia romana la importancia política y religiosa de la sociedad portuguesa, que lideraban Alfonso Enríquez y Juan Peculiar, con su estimable aportación a la reconquista cristiana, y al mismo tiempo se ponía de manifiesto el distanciamiento de su dominio respecto del de los reyes de Castilla y León, reinos que de nuevo marchaban por separado tras la muerte del emperador Alfonso VII. Por Castilla pasa fugazmente Sancho III (1157-1158), dando lugar al largo reinado de Alfonso VIII el Noble (1158-1214), mientras en León, reino al que correspondía el territorio portugués, gobierna Fernando II (1157-1188)59.

En cuanto a la colaboración de la iglesia local, corporativamente considerada, sigo sin ver muestras claras de la voluntad de portuguesismo y de independencia que normalmente se da como segura. En primer lugar cabe preguntarse qué iglesias locales vamos considerar. ¿Incluimos, junto a las de Braga, las de sus diócesis sufragáneas en Galicia y León? ¿Excluimos las de las diócesis portuguesas sufragáneas de Santiago de Compostela? Hay más interrogantes. Sabemos a quien tenía que obedecer teóricamente cada iglesia; pero, en verdad, ¿a quién obedecían las iglesias, es decir, los rectores y fieles, de unas y otras? ¿Significaba algo para la independencia el depender en la disciplina eclesiástica de un obispo u otro, de un curado o de otro? Y en cuanto a las orientaciones que recibían, ¿cabe decir, por acaso, que eran en algún modo nacionalistas, sea portuguesistas, galleguistas o leonesistas?

Se puede objetar que en el ámbito de la disciplina eclesiástica y de la doctrína y práctica de la fe no había apenas lugar a orientaciones religiosas particulares, puesto que, de principio, eran comunes para todos los cristianos, incluyendo el modo de celebración del culto divino, una vez generalizado el rito romano, aunque todavía no estuviera aceptado del todo, y no sólo en Portugal sino también en otras iglesias de la cristiandad peninsular ${ }^{60}$. No obstante, las prácticas religiosas tienen siempre una carga particularista, de acomodación a los modos de expresar en cada lugar los sentimientos de fe, a los usos y costumbres locales; y como es sabido, dan lugar en no pocas ocasiones a desviaciones prácticas y a doctrinas heréticas.

58 ERdMANN, Carl: O papado..., pp. 9, 13, 35.37.

59 Maria João Violante BRANCO, en el trabajo citado, «Portugal no reino de León», en pp. 604623, bajo el subtítulo: Epílogo: as bases de uma revisão, ofrece un buen resumen de la evolución de los aconteceres políticos y religiosos de Portugal entre 1128 y 1179: consolidación interna, proceso de desalineamiento con Castilla y León, fortalecimiento de la iglesia local con Braga como cabeza y de las relaciones directas con Roma. Su análisis me parece acertado en líneas generales, si bien no coincido del todo con sus apreciaciones referentes al papel político pro-independentista jugado por la iglesia local.

60 Cf. Olivar, Alexandre: «Les supèrvivences litúrgiques auctóctones a Catalunya en els manuscrits dels segles XI-XII», en Il Congrés Litúrgic de Montserrat, vol. III, Montserrat, 1967, pp. 21-89; PINELL, Jordi M., «El problema de las dos tradiciones del antiguo rito hispánico», en Liturgia y Música Mozárabes, Toledo, Instituto de Estudios Visigótico-Mozárabes de San Eugenio, 1978, pp. 3-8. 
En cualquier caso, no veo razón para sacar consecuencias de la divergencia o de la coincidencia en la manera popular de celebrar y vivir la fe cristiana, aspecto que escapa bastante del ámbito de influencia de la política, incluso en medio de divisiones en las altas esferas de la iglesia ${ }^{61}$. Lo que pretendo, al poner los interrogantes, es matizar que cuando afirmo que la iglesia local apoyó el proceso de la independencia portuguesa, no me refiero a todo el clero en general, sino a ciertos grupos selectos del clero y de las instituciones religiosas, cuya actividad, amen de religiosa era también política, y que colaboraron con Alfonso Enríquez y Juan Peculiar en Portugal y en la curia romana. La mayor parte del clero de las distintas diócesis y de los miembros de instituciones religiosas era extraña al tema, como lo era también el pueblo llano; se debían limitar a obedecer a sus señores, a sus superiores. De ahí, en parte, la gran permeabilidad de las fronteras, fuera de su indefinición durante largo tiempo. Con todo, es claro que Alfonso Enríquez y Juan Peculiar, como artífices diplomáticos principales, supieron ganar para su causa, no sólo la colaboración activa de los representantes de alto nivel de la iglesia portuguesa, sino también la aceptación pasiva y pacífica del resto.

Cabe, además, suponer que si la iglesia portuguesa y el propio poder civil condal hubieran orientado desde el principio mancomunadamente todos sus esfuerzos hacia la consecución de una identidad nacional dentro del ámbito eclesiástico, no se habrían conformado (pues, aunque no sin oposición, se conformaron) con que buena parte de las sedes portuguesas fueran sufragáneas de Santiago de Compostela hasta 1393-1394, aun considerando que, a su vez, Braga tuviera durante ese mismo tiempo como sufragáneas a varias sedes del reino castellano-leonés. Manuel Augusto Rodrigues, recogiendo el parecer general de los historiadores, califica esta división de diócesis sufragáneas de absurda ${ }^{62}$. Sin embargo, la mezcolanza de sedes sufragáneas no es tan ilógica, si nos situamos fuera de nacionalismos; obedece desde luego, y en primer lugar, a razones de diplomacia pontificia, pero ésta, a su vez, halla un razonamiento lógico en una cualidad eclesial que el papado utiliza con discreción: el a-fronterismo radical de la institución, en función de la universalidad de la fe cristiana.

La participación de las órdenes militares y de ciertos cargos importantes del clero portugués en la guerra santa contra los musulmanes, no es un dato que, por si mismo, tenga significado para la independencia. Pero, de hecho, jugó a favor, puesto que el terreno conquistado, o re-conquistado, se incorporó en su mayor parte al reino ya independiente, aunque no era una cuestión de independencia lo que se ponía en juego. No eran solamente luchas de poder, de simple ambición territorial para el reino portugués, se combatía también con el

61 Me refiero a la existencia de dos papas a la vez: papa y antipapa, según el reconocimiento que obtiene cada uno en las instituciones eclesiásticas y en los poderes civiles, y a las disputas entre obispos de diócesis vecinas.

62 Introducción a la edición del Livro Preto ..., p. CLXXXV: «Esta divisão, embora absurda, mantuve-se ao longo de 200 anos» 
fin de re-conquistar tierras para la fe cristiana, teniendo presente que la disparidad de fe en el ámbito peninsular no era sostenible en una sociedad occidental europea cristiana. Por eso, se cuenta con apoyos externos de cruzados, los cuales nada tienen que ver con intenciones independentistas. Recordemos que el obispo de Porto Pedro Pitões consiguió un cuerpo de 13.000 cruzados, entre ingleses, normandos, flamencos y alemanes para la conquista de Lisboa en octubre de1147; unos meses antes, los templarios habían intervenido en la toma de Santarem. Es en ese aspecto religioso de reconquista cristiana en el que se fundamenta la justificación de la guerra; por él la guerra, no sólo es justa, es santa. Y en él se inspira la aceptación de las conquistas como mérito excepcional por la Santa Sede ${ }^{63}$.

De otra parte, las dotaciones de iglesias y las donaciones al clero secular, a las instituciones religiosas y a las órdenes militares, de las que son beneficiarios directos principales los representantes de alto nivel a los que nos acabamos de referir, tienen un interés político que prima sobre cualquier otro. Alfonso Enríquez debió pensar, no sin razón, que la ganancia política derivada de esas aportaciones generosas superaba a la pérdida consecuente de poder económico regio. Como efecto inmediato, con ellas se garantizaba, en principio al menos, la adhesión activa o cuando menos pasiva de los mandos directivos de la iglesia y de las instituciones religiosas portuguesas a su causa. Luego, en su momento, cabría disminuir la «excesiva» potencialidad económica de la iglesia. De hecho sus sucesores se encargarían de ello, comenzando por su hijo Sancho I hasta llegar a los acuerdos de D. Dinís ${ }^{64}$.

Entre las instituciones religiosas puras, destacan tres, que contribuyeron desde su instalación a la creación de un clima cultural importante, no tanto autóctono como de irradiación, con resultados visibles al día de hoy: Santa Cruz de Coimbra (1131) y San Vicente de Fora (Lisboa, poco después de 1147), ambos monasterios de la orden de Canónigos Regulares de San Agustín; y el monasterio de Alcobaça (1153), de la orden del Cister. Los tres fueron dotados magníficamente, sobre todo Santa Cruz y Alcobaça.

El fruto de tan largo esfuerzo diplomático se vio recompensado en 1179 con el reconocimiento del rey y del reino, con todas sus consecuencias. Pocos años antes (1175) había muerto Juan Peculiar, mientras que Alfonso Enríquez pudo ver el feliz resultado de sus esfuerzos, si bien desde 1169, en que es heri-

63 VerísSIMO SERRÃO, Joaquim, História..., pp. 91-92, matiza acertadamente la afirmación de Carl Erdmann sobre la intencionalidad política y profana, más que religiosa, de la reconquista portuguesa bajo el mando de Alfonso Enríquez: «Pensamos que a tese de Erdmann carece de uma rectificação» (p.91); «Desta forma, a luta contra os Mouros obedecia no espírito régio a um pensamento de cruzada» (p.92).

64 Cf. Oliveira, Miguel de, História eclesiástica de Portugal, Lisboa ${ }^{4}, 1968$, pp. 116-124: «Contendas entre os reis e o clero»; Jorge, Ana Maria C. M. y VAsconcelos Vilar, Herminia, «Monarquia e Igreja: convergências e oposições», en Moreira AZEvedo, Carlos (Dir.), História Religiosa de Portugal, vol I, Lisboa, Temas e Debates, 2004, pp. 303-327. 
do y hecho prisionero en la batalla de Badajoz, era ya su hijo Sancho I quien se ocupaba de las tareas militares y en parte de las de gobierno. Alfonso Enríquez moría en 1185 con la aureola de ser el primer rey portugués.

Alfonso Enríquez jugó fuerte a ser rey total, sin vasallaje a ningún otro rey. El vasallaje a la Santa Sede, que busca y halla, es fundamentalmente de orden moral, no de orden propiamente político, aunque conlleva efectos políticos. Quiero decir que este vasallaje no le restaba al rey poder político real, aun cuando, además de los efectos de orden moral y político, que beneficiaban a ambas partes, tenía otros efectos de carácter económico, con carga para el reino y beneficio para el papado.

En la actuación papal, en este como en otros casos, se mezcla la teocracia con el a-fronterismo, elemento anterior a la teocracia y que se aviene muy bien con ella. Parte de un poder sin fronteras, de orden moral y espiritual, que en lo material se resuelve en el pago de censos, como señal de acatamiento. A la Santa Sede no le afecta la mayor o menor cohesión social a la que se haya podido llegar; ni le va ni le viene desde el punto de vista del reconocimiento del reino. Le importa y da por hecha, a través del rey y de sus conquistas, la cohesión de fe y en la fe. En ella ve la providencia divina. En realidad, como reconocen la mayoría de los historiadores que se ocupan del tema, el Papado no tenía interés en la acumulación de reinos, con sus correspondientes fronteras. Su idea de universalidad le hace a-fronteriza. Y esa misma idea le induce a dar su protección a los reinos que proclaman su independencia y constituyen fronteras. Es el modo del Papado de superar las fronteras, en lo que a él respecta.

En efecto, fuera de la teocracia papal, que le permite al papado ejercer el dominio total sobre los bautizados como súbditos suyos, aspecto que ponía al poder de la Iglesia un punto por encima del poder civil en el imperio y en los reinos cristianos, superando, ya que no ignorando, cualesquiera fronteras dentro del área de la cristiandad, hay otro factor de poder en manos de la iglesia, que es más radicalmente a-fronterizo y que está en la raíz de la teocracia papal: la conciencia de universalidad, de catolicidad de la iglesia, asumida como ingrediente natural, o sea, intrínseco a su naturaleza. Este factor, que entiendo es propio de toda creencia religiosa que se constituye en sociedad (en nuestro caso estamos ante una societas christiana), da lugar, no solamente a unos sentimientos, a una filosofía y a una idea determinada del mundo y de la existencia humana, sino también a un tipo de convivencia, a un derecho, lo cual resulta lógico si hemos de aceptar, como parece obligado, el principio: ubi societas, ibi ius.

Esta particularidad se pone de manifiesto en las relaciones de la iglesia con la sociedad civil en general y en la evolución de cada sociedad civil en concreto. Se establece así un entramado político-religioso en la relaciones mutuas, de modo que, mientras la sociedad civil camina fortaleciendo un espacio concreto donde desenvuelve su acción y obtiene su idiosincrasia: lengua, costumbres, derechos y deberes cívicos, la sociedad eclesial no ve, en cuanto a si misma, espacios concretos acotados para su actividad. Su mensaje es universal y salva 
las fronteras con la diplomacia. Pues, en efecto, son las fronteras de los reinos los que fuerzan la existencia de la diplomacia vaticana, que se ejerce a través de legados pontificios y de los obispos de cada reino. Si la diplomacia vaticana es la primera, se debe justamente a los dos aspectos de que estamos hablando. En primer lugar, a la universalidad de su presencia en el mundo, aspecto que la constituye en sociedad sin fronteras; y en segundo lugar, a la necesidad de establecerse entre fronteras, en sociedades civiles que demarcan fronteras para determinar su ámbito de poder.

De esta forma, el papado, con el imperio como tal en punto muerto, y a nivel práctico de simple reino, aunque conserve aún cierto valor teórico, se maneja entre fronteras. La Iglesia actúa sin bandazos, sin apenas mojarse. Se puede decir, en cierto modo, que en el ámbito de lo profano la Iglesia manda sin mandar, en cuanto que, salvo casos de emergencia, no manda de forma directa a los súbditos civiles en cuanto tales, sino que manda a quien manda ${ }^{65}$. Este aspecto del poder papal lo aprovecha muy bien el condado portugalense para convertirse definitivamente en reino y liberarse del vasallaje del reino castellano.

António A. Ferreira da Cruz resume los acontecimientos o situaciones de mayor relieve del primer rey de Portugal en los cuatro siguientes:1) determinación del joven infante en el momento de asumir personalmente las responsabilidades del gobierno del condado portugués, luchando incluso contra su madre; 2) expansión de las fronteras de su tierra; 3) acuerdos diplomáticos para acciones de guerra y para disponer de fuerzas necesarias a la defensa; 4) establecer y mantener las mejores relaciones con la iglesia ${ }^{66}$

\section{LA BULA MANIFESTIS PROBATUM}

La bula Manifestis probatum del papa Alejandro III, con fecha de 23 de mayo de 1179 , señala ordenadamente el camino que condujo a Alfonso Enríquez, con sus gentes nobles, hacia la constitución del reino de Portugal. Creo interesante fijar bien la atención en el documento, pues, aunque no es un texto original sino que responde a las normas de uso de la cancillería papal para casos de la misma naturaleza, se aviene en todo a la situación concreta que presenta-

65 Ejemplos de casos excepcionales o de emergencia son: la intromisión en la obediencia de los súbditos y la sentencia de entredicho del reino por causas estimadas de extraordinaria gravedad por el papado. Así, por conducta anticlerical de Alfonso II, Inocencio III lanzó un entredicho sobre el reino; e Inocencio IV, por razones del mismo tenor aún más graves absolvió a los súbditos de la obediencia debida al rey Sancho II, y les ordenó prestar obediencia al hermano de Sancho, Alfonso, conde de Boulogne, el cual, a la muerte de Sancho en su refugio de Toledo (1248), pasó a ser rey de Portugal con el nombre de Alfonso III.

66 Ferreira DA CruZ, António A.: "A situação política em Portugal em 1179», en $8^{\circ}$ Centenário do reconhecimento de Portugal pela Santa Sé (Bula "Manifestis probatum», 23 de maio de 1179), Comemoração Académica, Academia Portuguesa da História, Lisboa 1979, pp. 27-28. 
ba entonces Portugal. La bula culminaba un trabajo diplomático en el que el conde/rey y Juan Peculiar habían movilizado con decisión todas sus bazas posibles en el ámbito de lo político y de lo religioso. $\mathrm{Y}$ así se describe y reconoce en el documento.

Afirmada su transcendencia, sin embargo no entraré en comentarios detallados sobre la bula, pues ha sido analizada repetida y suficientemente ${ }^{67}$. Me limitaré a glosar el texto muy por encima, simplemente para conducir su lectura ${ }^{68}$.

Para empezar, nada que comentar sobre el encabezamiento, en su tenor epistolar habitual de saludo, fuera del significado patriótico que cabe dar al hecho de que por primera vez el papa se dirija a Alfonso Enríquez como rey de los portugueses, en consonancia lógica con la finalidad de la bula:

«Alexander episcopus, servus servorum Dei, karissimo in Christo filio Alfonso illustri portugalensium regi, eiusque heredibus, in perpetuum» $=$ «Alejandro obispo, siervo de los siervos de Dios, al muy querido hijo en Cristo Alfonso, rey ilustre de los portugueses, y a sus herederos, para siempre».

Punto primero. Expone el argumento fáctico, los considerandos de hecho que motivan y hacen equitativo el reconocimiento. Se concreta en la guerra santa contra los enemigos del nombre cristiano, que se complementa con la expansión de la fe cristiana, a lo que se añaden donaciones abundantes a la sacrosanta madre iglesia: fundaciones de monasterios, dotaciones de iglesias, etc. Este mérito se personaliza en la figura del rey:

«Manifestis probatum est argumentis, quod per sudores bellicos et certamina militaria, inimicorum christiani nominis intrepidus extirpator, et propagator diligens fidei christiane, sicut bonus filius et princeps catholicus, multimoda obsequia matri tue sacrosancte ecclesie impendisti, dignum memoria nomen et exemplum imitabile posteris derelinquens» $=$ «Se ha probado de forma evidente que, como buen hijo y príncipe católico, has prestado muchos servicios a tu madre la santa iglesia; te has convertido en un exterminador intrépido de los enemigos del nombre cristiano con grandes esfuerzos bélicos y combates militares y en un propagador diligente de la fe cristiana, dejando a la posteridad un nombre digno de ser recordado y un ejemplo a seguir».

Punto segundo. Expone los argumentos que podemos denominar canónicos, los considerandos morales y de derecho, en cuanto se refieren a las cuali-

67 Remito a los estudios incluidos en la publicación: $8^{\circ}$ Centenário do reconhecimento de Portugal pela Santa Sé (Bula «Manifestis probatum», 23 de maio de 1179), Comemoração Académica, Academia Portuguesa da História, Lisboa 1979; y al de Violante Branco, Maria J.: Poder Real e Eclesiásticos: a evolução do conceito de soberania régia e a sua relação com a praxis política de Sancho I e Alfonso II. Prólogo: 1179: A Manifestis probatum e o perfilar dos problemas [tese de doutoramento policopiada], Lisboa, Universidade Aberta, 1999, pp. 38-61. Con la bibliografía citada en ambas publicaciones.

68 El texto de la bula lo transcribo del original conservado en el Arquivo Nacional da Torre do Tombo, que se puede consultar on line. 
dades que deben adornar y adornan, en el caso, la figura del rey. Señala la teoría y la predica del rey:

«Equum est, autem, ut quos ad regimen et salutem populi ab alto dispensatio celestis elegit, apostolica sedes affectione sincera diligat, et in iustis postulationibus studeat efficaciter exaudire. Proinde nos, attendentes personam tuam, prudentia ornatam, iustitia preditam atque ad populi regimen idoneam $[\ldots] »=$ «Ahora bien, es razonable que la sede apostólica aprecie con afecto sincero a los que la providencia divina ha elegido para el gobierno y el bienestar del pueblo, y que se afane por atenderles eficazmente en sus justas súplicas. Por consiguiente, nos, atendiendo a tu persona, adornada de prudencia, dotada de justicia y apta para el gobierno del pueblo [...]».

En estos dos puntos de la bula se nos revela la razón de fondo que se alega frente a los otros, es decir, los territorios cristianos vecinos, para justificar el reconocimiento del territorio portugués como reino y de la dignidad regia de Alfonso Henriquez y sus sucesores. Son el eje sobre el que gira el resto de la bula. En primer lugar, se enumeran los servicios prestados por el príncipe a la santa madre iglesia, como católico y buen hijo, mediante sus proezas militares contra los infieles y la expansión consiguiente de la fe cristiana (fomento de la vida religiosa y dotación del clero), constituyendo un ejemplo digno de ser recordado e imitado. Acto seguido, se establece la conexión de estos méritos con la disponibilidad que la parte beneficiada por tales acciones meritorias ha de tener lógicamente en relación a las peticiones que se presumen justas del interesado. Se presumen así, justas, porque no se está ante una simple teoría, sino en un caso concreto, ante una petición formal, que la santa sede viene valorando desde tiempo atrás. Hay un trayecto de méritos continuados, que muestran, según los criterios de la santa sede, la justicia de la solicitud. Procede por tanto aceptarla con la solemnidad acostumbrada. No se trata en absoluto de una concesión forzada, conseguida por una presión del momento, como sucediera cuarenta años antes en el reconocimiento de Rogerio II como rey de Sicilia. La presión ejercida en el caso portugués no se salió (no consta que se saliera) de los cauces diplomáticos, fuera de que Portugal en el momento de su reconocimiento como reino por la Santa Sede ya estaba constituido de hecho como tal.

Punto tercero. Declaración del reconocimiento, que se personaliza en la figura del rey, al igual que los méritos y las cualidades, y se expresa en la recepción del rey y del reino bajo la protección de san Pedro y del papado:

«[...] eam [persona del rey Alfonso] sub beati Petri et nostra protectione suscipimus et regnum portugalense cum integritate honoris regni et dignitate que ad reges pertinet necnon et omnia loca que cum auxilio celestis gratie de sarracenorum manibus eripueris, in quibus ius sibi non possunt christiani principes circumpositi vendicare, excellentie tue concedimus et auctoritate apostolica confirmamus» $=$ «[...] la recibimos bajo la protección de san Pedro y nuestra, y concedemos y con autoridad apostólica confirmamos a tu excelencia el reino de 
Portugal, con la integridad del honor del reino y con la dignidad que corresponde a los reyes, así como todos los lugares que con la ayuda de la gracia divina liberares de las manos de los sarracenos, en los cuales los príncipes cristianos vecinos no pueden reivindicar el derecho para si».

En este punto me cabe una duda de interpretación respecto a la cláusula: «in quibus ius sibi non possunt christiani principes circumpositi vendicare» $=$ en los cuales los príncipes cristianos no pueden reivindicar el derecho para si. ¿Es limitativa sólo para los príncipes cristianos de los reinos vecinos, es decir, León y Castilla, que no podrían reivindicar terreno alguno de los conquistados por el rey portugués? Así veo que viene entendida por Luís Ribeiro Soares ${ }^{69}$. Por mi parte, creo que la cláusula admite otra interpretación, que considero más ajustada en el contexto histórico y en el texto mismo de la bula. Estimo que la cláusula es limitativa también para el rey portugués al tiempo que para sus vecinos; es doblemente limitativa. De una parte, limita al rey portugués en cuanto le corresponden todos los lugares conquistados por él, salvo aquellos que otros príncipes cristianos vecinos pudieren reivindicar como propios, o sea, de su derecho. De otra parte, limita a los príncipes cristianos vecinos, los cuales no podrán reivindicar para si aquellos lugares sobre los que no tengan derecho. En orden a la defensa y protección papal del rey y de los territorios portugueses frente a las posibles ambiciones de cualesquiera otros, hay ya otro apartado ad hoc en la bula:

«Decernimus ergo ut nulli omnino hominum liceat personam tuam aut heredum tuorum, vel etiam prefatum regnum, temere perturbare aut eius possessiones auferre vel ablatas retinere, minuere, aut aliquibus vexationibus fatigare» $=$ «Decretamos, por tanto, que a nadie le esté permitido perturbar temerariamente a tu persona, o a tus herederos, o al reino referido, ni apoderarse de sus dominios, o retener, disminuir o importunar con cualesquiera vejaciones lo arrebatado».

Punto cuarto. Sentados los argumentos y la concesión en su formulación básica, vienen las contraprestaciones por parte del papado al rey/reino y viceversa, del rey/reino al papado: extender la concesión hecha al rey a sus herederos, por parte del papado; y por parte del rey, mantener el comportamiento filial y la concreción del vasallaje en una cantidad pecuniaria anual de dos marcos de oro para el papa y sus sucesores:

«Ut autem ad devotionem et obsequium beati Petri apostolorum principis et sacrosancte romane ecclesie vehementius accendaris, hec ipsa prefatis heredibus tuis duximus concedenda, eosque super his que concessa sunt, Deo propitio, pro

69 Ribeiro SoAReS, Luís: «A bula «Manifestis probatum»e a legitimidade portuguesa», en $8^{\circ}$ Centenário do Reconbecimento de Portugal pela Santa Sé (Bula «Manifestis probatum» - 23 de maio de 1179), Lisboa, Academia Portuguesa da História, 1979, p. 151: «... e concede-lhe a posse das novas terras conquistadas aos sarracenos sem que ninguém possa contestar esse direito»; y más por extenso en las pp. 181-183. 
injuncti nobis apostolatus officio defendemus. Tua itaque intererit, fili karissime, ita circa honores et obsequium matris tue sacrosancte romane ecclesie humilem et devotum existere, et sic te ipsum in eius oportunitatibus et dilatandis christiane fidei finibus exercere, ut de tam devoto et glorioso filio sede apostolica gratuletur, et in eius amore quiescat. Ad indicium autem quod prescriptum regnum beati Petri iuris existat, pro amplioris reverentie argumento, statuisti duas marcas auri annis singulis nobis nostrisque successoribus persolvendas. Quem utique censum ad utilitatem nostram et successorum nostrorum Bracharensi archiepiscopo, qui pro tempore fuerit, tu et successores tui curabitis assignare» = "Ahora bien, para que te enciendas aún más en la devoción y servicio de san Pedro, príncipe de los apóstoles, y de la sacrosanta iglesia de Roma, hemos decidido hacer la misma concesión a tus herederos, a los que defenderemos en todo lo referente a la concesión, con la ayuda de Dios, conforme lo exige nuestro oficio apostólico. Por tu parte, hijo carísimo, procura mostrarte humilde y devoto de tu sacrosanta madre iglesia con trato reverente y obsequioso, y de esta manera ejercitarte en la defensa y expansión de la fe cristiana, de modo que la sede apostólica se felicite de tan devoto y glorioso hijo, y se sienta segura de su afecto. De otra parte, como señal de que el referido reino pertenece a san Pedro, como prueba de mayor reverencia, decidiste pagar dos marcos de oro anualmente a Nos y a nuestros sucesores. Tú y tus sucesores procuraréis que dicho censo, para utilidad nuestra y de nuestros sucesores, sea asignado al arzobispo de Braga que lo fuere en cada momento».

Punto quinto. Aquí viene la declaración de defensa del rey y reino portugués por parte de la sede apostólica, conforme a las disposiciones de la bula. La primera parte del texto la he dado al final del punto tercero, porque hace referencia directa a la persona del rey y a los territorios del reino. La segunda parte del texto se refiere al contenido de la bula en su totalidad, en los términos habituales, castigando a los que no la respeten y premiando a los que la guarden:

«Si qua igitur in futurum ecclesiastica secularisve persona hanc nostre constitutionis paginam sciens contra eam temere venire temptaverit, secundo tertiove commonita, nisi reatum suum digna satisfactione correxerit, potestatis honorisque sui dignitate careat, reamque se divino iudicio existere de perpetrata iniquitate cognoscat et a sacratisimo corpore ac sanguine Dei et domini redemptoris nostri Ihesuchristi aliena fiat, atque in extremo districte ultioni subiaceat. Cunctis autem eidem regno et regi sua iura servantibus, sit pax domini Ihesuchristi, quatinus et hic fructum bone actionis percipiant et apud districtum iudicem premia eterne pacis inveniant. Amen. Amen»= «Por tanto, si alguna persona, sea eclesiástica o seglar, intentara ir a sabiendas contra el contenido de nuestra constitución, y amonestada por segunda y tercera vez, no corrigiera su culpa con una satisfación digna, sea privada de la dignidad de su poder y honor, y sepa que se hace rea ante el juicio de Dios por la iniquidad cometida, se excluye de la participación del santísimo cuerpo y sangre de nuestro señor Jesucristo Dios y redentor y a la hora de la muerte queda sujeto al castigo implacable. Sin embargo, para los que observen los derechos del reino y del rey sea la paz de nuestro señor Jesucristo, de modo que perciban aquí el fruto de su buen hacer y hallen ante el juez inflexible el premio de la paz eterna. Amen. Amen». 


\section{A MODO DE CONCLUSIÓN}

En el proceso de independencia de Portugal hubo más fuerza y determinación por parte de los poderes civiles, que se mostraron más conscientes de lo que estaba en juego, que por parte de la iglesia local y de las instituciones religiosas. El ámbito público de dominio de los poderes civiles, con Alfonso Enríquez a la cabeza, fue protagonista desde el primer momento y se constituyó en el elemento axial de la independencia portuguesa, desarrollando todas sus armas: de guerra y paz, de treguas y pactos.

La ayuda de la iglesia local se concretó en la persona de Juan Peculiar y su entorno, prácticamente sin más participación directa institucional religiosa. No se ven razones para afirmar que se consiguió la constitución de una iglesia portuguesa, si es que cabe hablar con propiedad de independencia desde el punto de vista de la iglesia, cosa que me inclino a negar; o, cuando menos, pongo en duda. El entramado político religioso se establece entre Alfonso Enríquez con sus nobles por un lado y el arzobispo Juan Peculiar con su limitado entorno eclesial por otro; y la baza decisiva se juega en la curia romana más que en Portugal.

En cuanto al pueblo, es decir, a los súbditos del poder, poder que no siempre es un príncipe o un rey, sino que puede ser un señor, un dominus, apenas gozan de la palabra, sino que están a lo que se les diga o se les prometa, se les conceda o se les mande por su autoridad más cercana. Por ello, su actuación en el proceso de creación de un reino, en el caso del reino portugués, se la debe considerar en cierto modo pasiva, fuera del protagonismo que se le suele conceder en la historiografía y, en concreto, del que observo que se le otorga en los escritos sobre el tema que he tenido a mano.

Así pues, las iglesias, las instituciones religiosas y el pueblo, más que querer y buscar la independencia, la aceptaron, y la vivieron con sus venturas y sus desventuras.

El papado reconoció al $d u x$ de Portugal como rey y, consiguientemente, a su territorio como reino, bajo su tutela y protección, en 1179 , treinta y seis años después de la primera solicitud, en 1143, durante los cuales los protagonistas de la independencia se dedicaron a hacer ver al papado la viabilidad de Portugal como reino independiente dentro de una Hispania plurimonárquica. El papado, no se dedica a crear reinos ni a deshacerlos, pero sí puede contribuir, y contribuye de hecho, a que un territorio cuyo señor, príncipe o dux se somete a su protección, adquiera una protección liberadora hasta cierto punto de otras protecciones; y a reconocer a ese territorio como reino, bajo su protección. Así lo hizo con Portugal.

Tampoco debemos olvidar la relatividad de los conceptos que empleamos para significar la soberanía de un territorio con respecto a aquel otro del que se consideraba dependiente. Cabe preguntarse en este sentido qué soberanía buscaba en su momento el primer rey portugués, aún vasallo del castellano; y qué tipo de independencia, es decir, a qué contenido o riqueza de elementos de 
independencia aspiraba y hasta qué punto consiguió esa aspiración. De 1128 a 1143 y de 1143 a 1179 dio Portugal los primeros pasos de su caminar independiente, que acabaría siendo definitivo, no sin haber tenido que superar muchas y graves turbulencias, internas y externas, hasta su consolidación. 